\title{
Effect of Papain gel on Orthodontic Bracket Bonding: A Comparative Study
}

\author{
Authors \\ Dr Sayyed Mohammed SMA Qadri ${ }^{1}$, Dr Sunilkumar P. ${ }^{2}$, Dr Akash B Lavate ${ }^{3}$, \\ Dr Keval N. Bahuva ${ }^{4}$, Dr Divya S. Kharat ${ }^{5}$, Dr Misba SM Qadri6 \\ ${ }^{1}$ Post Graduate student in Dept of Orthodontics, ${ }^{2} \mathrm{MDS}$ in Orthodontics, Professor and HOD \\ ${ }^{3}$ MDS in Orthodontics, Reader, ${ }^{4,5}$ Post Graduate student in Dept of Orthodontics \\ ${ }^{6}$ BDS, Private Practitioner \\ Pandit Deendayal Upadhyay Dental College 19/1, Kegaon Solapur- 413 255, Dist- Solapur State- \\ Maharashtra India \\ Corresponding Author \\ Dr Sayyed Mohammed Qadri \\ Plot No 5, Sahil Nagar, Hotgi Road, Post - Tikekarwadi. Solapur - 413005 \\ Phone No - 0217 2605400, Mobile No- +91 9096453018 \\ Email: drpriyatamkarade@gmail.com
}

\begin{abstract}
Objective: The purpose of this study was to verify the hypothesis that papain gel at concentrations of $8 \%$ and $10 \%$ prior to orthodontic bonding increases shear bond strength.

Materials and Method: 30 pre-molar teeth extracted for orthodontic purpose were divided into three groups [n=10]. Group I acted as a control in which brackets were bonded with Trans bond XT [3M Unitek], group II and group III were treated with $8 \%$ and $10 \%$ papain gel respectively prior to bracket bonding with Trans bond XT. The bonded samples were then stored in artificial saliva for 24 hours at room temperature. Samples were subjected to mechanical testing in Universal Instrom Testing Machine. The values obtained were submitted to Analysis of Variance and post-hoc Tukey test.

Results: Highest bond strength values were seen in group III in which 10\% papain gel was applied before bonding; then followed by control group.

Conclusion: It can be concluded that application of 10\% papain gel can increases bond strength of brackets when compared to conventional bonding procedure with Trans bond XT.

Keywords: Effects of papain gel, Orthodontic bracket bonding, Papain gel, Shear bond strength.
\end{abstract}

\section{Introduction}

Enamel decalcification and white spot lesions (WSL) are common problems associated with orthodontic treatment, caused by plaque accumulation and bacterial attack on the enamel surface. ${ }^{1}$ During orthodontic treatment, formation of white spot lesions (WSLs) around brackets has long been recognized as a potential risk. ${ }^{2}$ White stain lesions and also marginal gingivitis are concern to the majority of orthodontists; oral hygiene measures and the use of new materials help to prevent these intercurrences. ${ }^{3,4}$ WSLs, a 
clinically detectable manifestation of subsurface enamel demineralization, represent the early stages of caries formation. ${ }^{5}$ WSLs exhibit up to $50 \%$ reduction in enamel mineral loss, due to mineral loss, there are changes in hardness and refractive index of the enamel, causing scattering of light giving enamel chalky, opaque appearance. ${ }^{1,2} \mathrm{~A}$ large-scale study by Julien $\mathrm{KC}$ et al found that $23.4 \%$ of patients develop at least one clinically visible white spot lesion during their course of treatment. ${ }^{6}$

Elimination of organic substances from the enamel surface before acid etching increases the resistance to orthodontic traction by providing a better acid etching pattern on enamel. ${ }^{7}$ Glass ionomer cements (GICs) are outstanding as they allow chemical bonding to both enamel and dentin, in addition to releasing fluoride into the oral medium, accumulating and recharging themselves. ${ }^{8}$ In spite of all favorable characteristics, GICs do not provide adequate retention to enamel, resulting in a deficient bond between orthodontic accessories and enamel. ${ }^{9}$

Several strategies are suggested to prevent the development of WSL. Fluoride ions delivered through mouth rinses, varnishes, gels, and fluoridereleasing cements have been reported to reduce the extent and incidence of WSLs during orthodontic treatment with fixed appliances. ${ }^{10}$ Deproteinization of the enamel surface by removal of plaque layer adhered to the tooth surface before bracket bonding was first proposed by Justus et $\mathrm{al}^{7}$ using $5.25 \%$ sodium hypochlorite $(\mathrm{NaOCl})$ for this purpose. The solution was called GK-101; [brand name Caridex] or N-monochloroglycine composed of; sodium hydroxide, sodium chloride, glycine, and $0.05 \%$ $\mathrm{NaOCl}$ was efficient at removing carious lesions. $\mathrm{NaOCl}$ eliminates the organic matter present on the enamel surface by dissolving it. ${ }^{11,12}$

In the 1980s, Swedish researchers patented a product, initially called "Demex" and, later, "Carisolv", composed of amino acids and $\mathrm{NaOCl}$, in gel form. ${ }^{13}$ Considering the advantages of Carisolv due to its longer action time, a gel was developed in Brazil in 2003, based on papain, chloramines, and toluidine blue and called "Papacarie" (meaning "eating caries"). ${ }^{14,15}$ Studies conducted by Pithon MM et $\mathrm{al}^{9}$ concluded that out of substances with similar properties of deproteinizing, $10 \%$ papain is outstanding before etching.

Papain is extracted from the latex of the Carica papaya, belonging to the Caricaceae family, better known as the papaya (pawpaw). ${ }^{16}$ It is a proteolytic cysteine enzyme with antibacterial and antiinflammatory properties, and it acts as an agent for removing debris without any harmful effect on tissues because of the specificity of the enzyme. ${ }^{17,18}$ It is used with the aim of removing infected tissue without causing any damage to any healthy structure in the mouth, and requires neither instruments with cutting edges nor rotary instruments. ${ }^{18}$ There are not many studies done to check its clinical effectiveness in enhancing bond strength of enamel surface. This study is aimed to verify the hypothesis that papain gel prior to orthodontic bonding increases shear bond strength.

\section{Materials and Method}

The study consisted of 30 pre-molars divided into three groups extracted for orthodontic purposes, stored in thymol solution $(0.1 \% \mathrm{wt} / \mathrm{vol})$ to prevent dehydration and bacterial growth. Each tooth was thoroughly scaled to remove calculus and softtissue debris followed by thorough prophylaxis with pumice on rubber cup mounted on a slowspeed contra-angle headpiece. The extracted premolars were mounted in cold cure acrylic resin of blocks 2 X 2 square $\mathrm{cm}$.

Maxillary and mandibular pre-molars extracted for orthodontic reasons with intact buccal surfaces having sound coronal surface were included in the study while pre-molars with large restorations, fracture during extraction, caries or decay, macroscopic cracks, abrasions or hypo-calcified enamel or prior exposure to chemicals which may affect the strength of the enamel were excluded.

In group I, enamel conditioning was carried out with $37 \%$ phosphoric acid solution. The etchant was then rinsed off with an air-water spray for 30 
seconds and then air dried. Group II and group III were deproteinized with $8 \%$ and $10 \%$ papain gel followed by acid etching with $37 \%$ phosphoric acid and then rinsed off. All samples were bonded with metal brackets (Modern Orthodontics) using Transbond XT [3M Unitek] primer and bonding adhesive. A small amount of adhesive resin was placed on base of the uncoated brackets and brackets were placed on the tooth surfaces, adjusted to their final positions. After removal of excess resin from the periphery of the bracket base, light curing was done for 20 seconds by using a rechargeable LED curing light (LY-C240, Unicorn; DenMart).

All the specimen were then stored in artificial saliva for a period of 24 hours at room temperature. De-bonding was carried out after 24 hours by using bracket de-bonding pliers following a standardized procedure - the brackets were de-bonded using bracket de-bonding pliers by gripping below the bracket wings at bracket-enamel interface, a rotational axis was created at apical bracket margin, thereby releasing the bracket.

After bracket removal, teeth were examined for residual adhesive on the pre-molars using a modified Adhesive Remnant Index by Artun $\mathbf{J}$ and Bergland $S^{19}$ to record the site for bond failure. The scoring criteria are as follows;

Score $0=$ No adhesive left on tooth

Score $1=$ Less than half of the adhesive left on tooth

Score $2=$ More than half of the adhesive left on tooth

Score 3 = All adhesive left on tooth, with distinct impression of bracket mesh.

Each tooth was subjected to a shear load in a Universal Testing Machine, applied with a knifeedged blade at a cross-head speed of $0.5 \mathrm{~mm} / \mathrm{min}$. The force was applied parallel to the tooth surface on top of each orthodontic bracket base, and the shear load was recorded at the point of failure. The upper member of the machine was fitted with a chisel shaped blade which was positioned in the occluso-gingival direction and to make contact with the bonded specimen (Fig 1). The force per unit area required to dislodge the bracket was then calculated and recorded as the shear bond strength. [Fig 1]

\section{Statistical Analysis}

Descriptive statistics that included mean, standard deviation, median, and minimum and maximum values were calculated for all eight groups. Analysis of variance was applied to determine whether there were significant differences among the groups. Post hoc- Tukey test was used for comparing the three groups.

\section{Results}

The results of the shear bond strength test under UTM demonstrated highest bond strength values for group III (Table 1) in which $10 \%$ papain were used, which differed statistically from the other two groups $(\mathrm{p}<0.05)$. The lowest values were recorded for group II where $8 \%$ papain gel was used. In relation to ARI values, not much statistical difference was seen between group I and III (Table 2).

Table 1. Minimum, maximum, mean, and SD of shear bond values. $\mathrm{P}$ value* $=$ Significant

\begin{tabular}{|l|c|c|c|c|}
\hline Groups & Minimum & Maximum & $\begin{array}{c}\text { Mean } \\
(\mathrm{SD})\end{array}$ & $\begin{array}{c}\text { P } \\
\text { value }\end{array}$ \\
\hline I & 5.5 & 12.2 & $6.7(2.4)$ & .16 \\
\hline II & 3.7 & 10.8 & $5.9(2.1)$ & .72 \\
\hline III & 4.8 & 13.7 & $7.1(1.6)$ & $.00^{*}$ \\
\hline
\end{tabular}

Table 2. Mean ARI values of the groups, $\mathrm{P}$ value*= Significant

\begin{tabular}{|l|c|c|}
\hline Groups & Mean & P value \\
\hline I & 2.1 & II, $\mathrm{P}^{*}=.00$ \\
\cline { 3 - 3 } & & III, $\mathrm{P}=.17$ \\
\hline II & 2.6 & III, $\mathrm{P}^{*}=.00$ \\
\hline III & 1.7 & - \\
\hline
\end{tabular}

Fig 1 UTM to evaluate shear bond strength

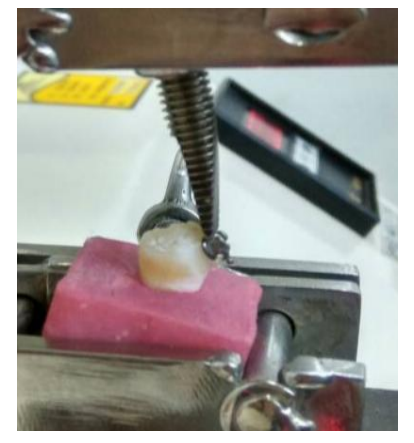




\section{Discussion}

The literature is abundantly rich with various experimental studies mostly on extracted pre-molar teeth, regarding bond strength of newer adhesives, potential side-effects of various de-bonding techniques with comparison of techniques for remnant adhesive removal methods. The finishing and polishing procedures are usually aimed at restoring the topographic enamel surface and preserving the integrity of enamel as close to its pre-treatment condition. Cracks, scratches or enamel fracture are sometimes unavoidable causing irreversible alteration of enamel surface. ${ }^{20}$

In conjunction with these harmful effects, decalcification or demineralization is also an important effect of orthodontic therapy on tooth enamel as orthodontic accessories and their bonding materials create retentive areas around them for bacterial biofilm accumulation. ${ }^{21,22}$ Improper or poor oral hygiene measures or patient inability to meet the minimum hygiene maintenance demands can also a play a crucial role in aggravating the formation of white spot lesions adjacent to orthodontic brackets and accessories thereby increasing the risk of dental caries and marginal gingivitis.

To minimize and prevent white spot lesions, awareness about the use of fluoride-releasing materials increased. Glass ionomer cements were developed with the aim of uniting biological and chemical properties in one and the same material. Glass ionomer cements developed by Wilson and Kent allow chemical bonding to enamel, dentin, and other surfaces, in addition to releasing fluoride. $^{23}$ However, these cements have lower bond strength to the enamel surface in comparison with orthodontic composites which cause frequent de-bonding delaying the treatment duration.

Carisolv, a product that contains $\mathrm{NaOCl}$ used in endodontic treatment, ruptures the cross links between the dentinal collagen fibrils, denaturing them and dissolving the necrotic tissue. The bond between $\mathrm{NaOCl}$ and the amino acid reduces the effect of whole collagen denaturing and rupturing only the link between the affected collagen fibrils, without any molecular alterations occurring. ${ }^{24}$

The bond strength between orthodontic accessories and enamel may be compromised by the presence of the acquired pellicle at the time when they are being bonded. ${ }^{25}$ There is ample evidence that it is formed by selective adsorption of proteins, peptides, and other molecules present in oral fluid. It is well known because it is a biologically important integument on the tooth surface as it constitutes the interface between the enamel surface and the first layer of oral biofilm. It is recognized that at a functional level, it plays a role in mineral homeostasis of tooth enamel. ${ }^{26}$ This membrane is a biofilm free of bacterial colonization, and its most abundant components are proteins, glycoproteins, enzymes, and mucins or their derivatives. ${ }^{27}$

Hence, removal of the acquired pellicle by deproteinizing it before performing orthodontic bracket bonding is vitally important. Deproteinization performed with papain gel removes the acquired pellicle, which persists after prophylaxis, from the tooth surface. Papain is extracted from the latex in the leaves and skin of the mature fruit. In addition to the proteolytic action, it has antibacterial and anti-inflammatory properties, thus acts as remover of necrotic remainders, and is not cytotoxic. $^{26}$ It is also stable under adverse conditions of temperature, humidity, and

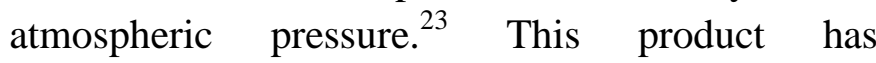
antimicrobial effectiveness, mainly regarding Streptococcus mutans and Lactobacillus. ${ }^{28}$

Papain gel used in the present study is not produced from pure papain but it is a mixture of chloramine a compound of chlorine and ammonia and toluidine blue dye and papain. This ingredient constitution was followed by taking guidelines from previous studies on papain gel by Pithon MM et al. ${ }^{23,26}$

The results found in this study indicate that the group III which was deproteinized with $10 \%$ papain gel followed by etching with $37 \%$ phosphoric acid obtained the best shear bond strength result in comparison with the group I and group II which was treated with $8 \%$ papain gel. This result is similar to the result of the study by Pithon MM et 
$\mathrm{al}^{26}$ in which they treated 180 bovine incisors with $2 \%, 4 \%, 6 \%, 8 \%$ and $10 \%$ papain along with control group which was bonded with resinmodified glass ionomer cement [RMGIC]. They concluded that enamel deproteinization with $8 \%$ and $10 \%$ papain gel increases shear bond strength of orthodontic brackets bonded with RMGIC.

Results which showed lower bond strength values can be explained as having lower mechanical retention between enamel surface and adhesive material and only chemical bonding occurred between them. Similar type of results were observed in study by Pithon MM et al. ${ }^{9}$ Earlier studies with papain gel used RMGIC for bonding, apart from being favorable for anti-cariogenic action they exhibit low bond strength values as compared to Transbond XT and other composite resins used for bonding.

Finally, the results presented here are preliminaries that are coming from an in-vitro study. In-vivo studies should be performed in order to confirm the findings. Removal of acquired pellicle in extracted teeth cannot be that evident as storage medium after extraction can also affect demineralization. This study is done with minimum sample size so to get statistically significant values we ought to increase the samples.

\section{Conclusions}

1. Papain helps to remove the biofilm or acquired pellicle from the tooth which helps better adhesion of brackets to enamel.

2. Increase in the concentration of papain gel can enhance bond strength values by deproteinizing the tooth surface, hence the hypothesis is proved.

3. Application of $10 \%$ papain gel before acid etching is an effective method to increase the shear bond strength values and also it reduces chances of cracks and fractures during de-bonding of orthodontic accessories.

Source(s) of support in the form of grants, equipment, drugs, or all of these: None

Sources of Funding: None

\section{References}

1. Gorelick L, Geiger AM, Gwinnett AJ. Incidence of white spot formation after bonding and banding. Am J Orthod. 1982;81: 93-8.

2. Sudjalim TR, Woods MG, Manton DJ. Prevention of white spot lesions in orthodontic practice: a contemporary review. Aust Dent J 2006;51:284-9.

3. Livas C, Kuijpers-Jagtman AM, Bronkhorst E, Derks A, Katsaros C. Quantification of white spot lesions around orthodontic brackets with image analysis. Angle Orthod. 2008; 78:585-90.

4. Bishara SE, Ostby AW. White spot lesions: formation, prevention and treatment. Semin Orthod. 2008; 14:174-82.

5. Ogaard B. Prevalence of white spot lesions in 19-year-olds: a study on untreated and orthodontically treated persons 5 years after treatment. Am J Orthod Dentofacial Orthop 1989;96:423-7.

6. Julien KC, Buschang PH, Campbell PM. Prevalance of white spot lesion formation during orthodontic treatment. Angle Orthod. 2013;83:641-7.

7. Justus R, Cubero T, Ondarza R, Morales F. A new technique with sodium hypochlorite to increase bracket shear bond strength of fluoride-releasing resin-modified glass ionomer cements: comparing shear bond strength of two adhesive systems with enamel surface deproteinization before etching. Semin Orthod. 2010;16:66-75.

8. dos Santos RL, Pithon MM, Vaitsman DS, Araujo MT, de Souza MM, Nojima MG. Long-term fluoride release from resinreinforced orthodontic cements following recharge with fluoride solution. Braz Dent J. 2010; 21:98-103.

9. Pithon MM, Dos Santos RL, de Oliveira MV, Ruellas AC, Romano FL. Metallic brackets bonded with resin-reinforced glass ionomer cements under different enamel conditions. Angle Orthod. 2006; 76:700-04. 
10. Geiger AM, Gorelick L, Gwinnett AJ, Benson BJ. Reducing white spot lesions in orthodontic populations with fluoride rinsing. Am J Orthod Dentofacial Orthop 1992;101:403-7.

11. De-Deus G, Souza EM, Marins JR, Reis C, Paciornik S, Zehnder M. Smear layer dissolution by peracetic acid of low concentration. Int Endod J.2011;44:485-90.

12. De Munck J, Ermis RB, Koshiro K, Inoue S, Ikeda T, Sano H, Van Landuyt KL, Van Meerbeek B. $\mathrm{NaOCl}$ degradation of a HEMA-free all-in-one adhesive bonded to enamel and dentin following two airblowing techniques. J Dent. 2007;35:74-83.

13. Medi Team Annual Report. Stockholm, Sweden: Medi Team Dentalutveckling I Göteborg; 1998.

14. Maragakis GM, Hahn P, Hellwig E. Clinical evaluation of chemomechanical caries removal in primary molars and its acceptance by patients. Caries Res 2001;35:205-10.

15. Bussadori SK, Castro LC, Galvao AC. Papain gel: A new chemo-mechanical caries removal agent. J Clin Pediatr Dent 2005;30:115-9.

16. Bruno LH, Guedes CC, Motta LJ, Santos EM, Bussadori SK. Comparacion entre la utilizacion de elementos rotatorios de baja velocidad y tratamiento quimico mecanico de caries dentinal en denticion decidua. Acta OdontologicaVenezolana.2009;47:1-9

17. Piva E, Ogliari FA, Moraes RR, Cora F, Henn S, Correr- Sobrinho L. Papain-based gel for biochemical caries removal: influence on microtensile bond strength to dentin. Braz Oral Res. 2008;22:364-370.

18. Motta LJ, Martins MD, Porta KP, Bussadori SK. Aesthetic restoration of deciduous anterior teeth after removal of carious tissue with Papacarie. Indian J Dent Res. 2009;20: 117-20.

19. Artun J, Bergland S. Clinical trials with crystal growth conditioning as an alternative to acid-etch enamel pretreatment. $A m J$ Orthod. 1984;85(4):333-40.

20. Leao Filho JCB, Braz AKS, De Souza TR, De Araujo RE, Pithon MM, Tanaka OM. Optical coherence tomography for debonding evaluation: An in-vitro qualitative study. Am J Orthod Dentofacial Orthop 2013;143(1):61-8.

21. Pithon MM, de Oliveira Ruellas AC, Sant'Anna EF, de Oliveira MV, Alves Bernardes LA. Shear bond strength of brackets bonded to enamel with a selfetching primer: effects of increasing storage time after activation. Angle Orthod. 2009; 79:133-7.

22. Bishara SE, Ostby AW. White spot lesions: formation, prevention, and treatment. Semin Orthod. 2008;14:174-82.

23. Pithon MM, Ferraz CS, Oliveira GC, Pereira TBJ, Oliveira DD, de Souza RA et al. Effect of $10 \%$ papain gel on enamel deproteinization before bonding procedure. Angle Orthod 2012;82:541-5.

24. Ericson D. In vitro effi cacy of a new gel for chemo-mechanical caries removal. J Dent Res 1998;77:1252.

25. Campoy MD, Vicente A, Bravo LA. Effect of saliva contamination on the shear bond strength of orthodontic brackets bonded with a self-etching primer. Angle Orthod. 2005; 75:865-69.

26. Pithon MM, Ferraz CS, Oliveira GC, Santos AMD. Effect of different concentrations of papain gel on orthodontic bracket bonding. Progress in Orthodontics 2013, 14:22.

27. Hannig C, Hannig M, Attin T. Enzymes in the acquired enamel pellicle. Eur J Oral Sci. 2005;113:2-13.

28. Lopes MC, Mascarini RC, da Silva BMCG, Florio FM, Basting RT. Effect of a Papainbased Gel for Chemo-mechanical Caries Removal on Dentin Shear Bond Strength. J Dent Child 2007;74:93-7. 